\title{
The effect of oral contraceptive pills on the macula, the retinal nerve fiber layer, the ganglion cell layer and the choroidal thickness
}

\author{
Yasmine Maher Shaaban ${ }^{1,2,3^{*}}$ (D) and Tamer Abdel Fattah Badran ${ }^{1,2}$ (D)
}

\begin{abstract}
Backgroun: To evaluate the effect of oral contraceptive pills (OCP) on the macula, the retinal nerve fiber layer (RNFL), the ganglion cell layer (GCL), and the choroidal thickness (CT).

Methods: In this prospective observational cross-sectional study, 60 eyes of 30 healthy women taking monophasic OCP (0.03 mg ethinylestradiol and $0.15 \mathrm{mg}$ levonorgestrel) for contraception for at least 1 year were compared with 60 eyes of a control group of 30 healthy women who were not taking any OCP. Spectral-Domain Optical Coherence Tomography (SD-OCT) was used to evaluate the macula, the RNFL, the GCL, and the CT. Measurements were taken in the follicular phase (day 3) of the last menstrual cycle in all women. The body mass index (BMI) scores of all participants were also recorded.

Results: No disparity in terms of age and BMI between both groups was observed ( $p=0.444, p=0.074$, respectively). All the macular parameters measurements were considerably lower in the OCP group compared to the control group $(p<0.001)$. Also, the RNFL thickness, the GCL thickness, and the CT were all significantly thinner in the OCP group $(p<$ $0.001)$.

Conclusions: The use of OCP can cause significant changes in the retina and choroid thickness over 1 year period. The women who are using OCP for a longer duration could have some eye problems. OCT should be routinely done for follow up. Further long term studies are required, using different preparations of OCP. It is important to find out when this thickness alterations can be clinically significant or symptomatic and if these changes are reversible or not.
\end{abstract}

Keywords: Oral contraceptive, Macula, Nerve fiber, Ganglion, Choroid, Ocular coherence tomography

\section{Background}

Oral contraceptive pills (OCP) are commonly used by women all over the world during their reproductive life. Several studies reported the occurrence of a variety of ocular disorders in women using OCP [1]. Estrogen and progesterone receptors have been observed in multiple ocular tissues, such as the choroid, retina, lens, conjunctiva, cornea, and the Meibomian gland [2]. Sex hormones

\footnotetext{
* Correspondence: yasminemaher0@gmail.com;

Yasminemaher@med.asu.edu.eg

'Department of Ophthalmology, Faculty of Medicine, Ain Shams University, Abbassyia, Cairo 11566, Egypt

${ }^{2}$ The Eye Subspecialty Center, (ESC), 18 El Khalifa El Maamoun Street,

Heliopolis, Cairo 11402, Egypt

Full list of author information is available at the end of the article
}

proved to affect the retina and the choroid and a correlation between sex hormones and retinal disorders have been described [2-4]. The macula is the central part of the retina and any degenerative changes in this area could affect the central vision. The macula, the (RNFL), the ganglion cell layer (GCL), and the choroidal thickness (CT) may decrease with age, degenerative diseases, ischemia, chronic inflammatory processes [5]. These changes may also be due to genetic, environmental, and hormonal factors [6]. Since oral contraceptive pills (OCP) usually contain estrogen and progesterone, the retina and choroid are at risk. In literature, there is very little data concerning the effect of OCP on the thickness of the macula, the RNFL, the GCL, and the CT [7]. In this study, we aim to evaluate

(c) The Author(s). 2019 Open Access This article is distributed under the terms of the Creative Commons Attribution 4.0 International License (http://creativecommons.org/licenses/by/4.0/), which permits unrestricted use, distribution, and reproduction in any medium, provided you give appropriate credit to the original author(s) and the source, provide a link to the Creative Commons license, and indicate if changes were made. The Creative Commons Public Domain Dedication waiver (http://creativecommons.org/publicdomain/zero/1.0/) applies to the data made available in this article, unless otherwise stated. 
the effect of OCP on the macula, the NFL, GCL, and the $\mathrm{CT}$, to address any reported complications or side effects to people who use OCP for contraception or for other reasons other than contraception and to consider regular ocular examination and follow up while using these pills.

\section{Methods}

Aim

Is to evaluate the thickness of the macula, the RNFL, the GCL, and the choroid using SD-OCT in women using the same OCP and compare them with those who do not use any OCP. Sixty eyes of 30 healthy women who had received OCP for more than 1 year (the OCP group) were compared with 60 eyes of healthy women who were not using any OCP (the control group). All participants were Egyptian women, in their reproductive age period of 23-36 years. Those who do not use OCP have a regular natural menstrual cycle of 28-30 days. All participants were evaluated in the follicular phase (day3) of their last menstrual cycle.

\section{Design}

An observational comparative cross-sectional study.

\section{Setting}

The study was performed in The Eye Subspecialty Center (ESC), Heliopolis, Cairo, Egypt.

The cases were recruited from patients visiting the Outpatient Clinic, and the OCT was performed in the Investigation Unit. All procedures in this study adhered to the Declaration of Helsinki's ethical principles for medical research involving human subjects and were approved by the Ethics Committee Of The Eye Subspecialty Center (ESC), 18 El Khalifa El Maamoun Street, Heliopolis, 11,402 Cairo, Egypt. Verbal informed consent was obtained from all participants.

All candidates had a complete ophthalmologic examination including medical history, visual acuity, cycloplegic refraction, Goldmann applanation tonometry, slit-lamp bio microscopy, and fundus examination. Those with the best-corrected visual acuity of $\geq 20 / 25$, spherical refraction within $\pm 3.00 \mathrm{D}$, and cylinder refraction within $\pm 1.50 \mathrm{D}$, and had normal ocular examination results were included in the study. Body mass index (BMI) of all candidates was also measured and compared in both groups based on the formula: $\mathrm{BMI}=($ weight $/$ height $\left.{ }^{2}\left[\mathrm{~kg} / \mathrm{m}^{2}\right]\right)$.

\section{Exclusion criteria}

Those who had previous ocular surgery, ocular trauma, uveitis, glaucoma, cataract, macular degeneration, and cystoid macular edema were excluded from the study. Pregnancy, diabetes mellitus, hypertension, cardiovascular events, thyroid disorders, Cushing disease, thromboembolic disease, cancer, chronic liver disease, kidney disease, pancreatitis, congenital adrenal hyperplasia, psychotic disorders, and those who use antidepressants, steroidal hormone, mood stabilizers, caffeine or tobacco were also excluded from the study.

The used OCP is a commonly prescribed type of combined oral contraceptive (COC) birth control in Egypt. It is monophasic pills having estrogen $(0.03 \mathrm{mg}$ ethinylestradiol) and progestin $(0.15 \mathrm{mg}$ levonorgestrel). Monophasic pills contain equal amounts of the hormones estrogen and progestin for an entire monthly cycle.

Spectral-Domain Optical Coherence Tomography (SD-OCT), Cirrus HD-OCT model 5000 (Carl Zeiss Meditec, Germany) was used to measure the thickness of macula, the RNFL, the GCL, and the CT. The procedure was done by the same person using the same OCT unit. The Scan Protocol was done as follows: Macular Cube Scan $512 \times 128$ was used for macular thickness, cube volume, cube average thickness, and ganglion cell layer thickness. The Optic Disc Cube $200 \times 200$ SCAN was used for RNFL thickness analysis. The Enhanced Depth Image Scan was used for choroidal thickness, in which three points were measured, subfoveal, $3 \mathrm{~mm}$ point nasal to the fovea and $3 \mathrm{~mm}$ point temporal to the fovea. The study was done in the period between January 2017 and October 2018.

\section{Statistics}

Quantitative data were presented as mean and standard deviation. Independent samples t-test was used to test the statistical significance of the difference of means of the two groups. $P$ values $\leq 0.05$ were considered significant. The Statistical Package for the Social Sciences SPSS version 20 for Windows (IBM Corp., Armonk, NY) was used for the statistical analysis.

\section{Results}

There was no disparity in terms of age and BMI between both the studied groups. The OCP group had a mean age of $30.48 \pm 3.4$ years while the control group had a mean age of $29.97 \pm 3.87$ years $(\mathrm{t}=0.777, p=$ 0.444). The mean BMI scores was $23.3+2.2 \mathrm{~kg} / \mathrm{m}^{2}$ for the OCP group and $22.3+2.3 \mathrm{~kg} / \mathrm{m}^{2}$ for the control group $(\mathrm{t}=1.818, P=0.074)$. BMI of $18.5-24.9 \mathrm{~kg} / \mathrm{m}^{2}$ is considered as normal. The difference between the two groups was statistically insignificant (Table 1). The OCP used in this study had a significant thinning effect on all the parameters of all parts of the macula $(p<$ $0.001)$, all parts of RNFL $(p<0.001)$, all parts of GCL $(p<0.001)$, subfoveal choroid, temporal and nasal choroid $3 \mathrm{~mm}$ points nasal and temporal to the fovea $(p<$ 0.001) (Tables 2, 3, 4). 
Table 1 Demographic data for oral contraceptive pills group and the control group

\begin{tabular}{llll}
\hline Parameter & OCP Group $(n=60)$ & Control Group $(n=60)$ & $\mathrm{t}$ \\
\hline Age, years & $30.48 \pm 3.4$ & $29.97 \pm 3.87$ & 0.777 \\
Gender & female & female & 0.444 \\
Number of subjects & 30 & 30 & \\
Ethnicity & Egyptians & Egyptians & \\
Study location & Cairo, Egypt & Cairo, Egypt & 1.818 \\
BMI. $\mathrm{kg} / \mathrm{m}^{2}$ & $23.3+2.2$ & $22.3+2.3$ & 0.074
\end{tabular}

OCP Oral contraceptive pills, BMI Body Mass Index, Values are expressed as mean \pm SD. $P$ values $\leq 0.05$ were considered significant

\section{Discussion}

Estrogen and progesterone receptors have been observed in different ocular tissues, such as the cornea, the conjunctiva, the Meibomian glands, the lens, the choroid, and the retina. The expression of estrogen and progesterone receptors in the eye is responsible for their ocular effects and various studies published in the literature about these receptors and their role in changing eye structures [2]. Oral Contraceptive Pills are widely used for contraception, but they are also indicated in menorrhagia, endometriosis, acne and hirsutism, fibroid uterus and premenstrual syndrome [8].

Reviewing the impact of combined oral contraceptives on ocular tissues showed that the OCP has multiple adverse effects on ocular tissues [1], which include dry eye symptoms related to decreased lipid production [9], asymptomatic corneal edema, contact lenses discomfort and intolerance [10]. Significant increase in the central corneal thickness values was also reported in patients using OCP [11]. There are also retinal neuroophthalmologic complications involving the 6th cranial nerve paralysis, parietal syndrome, hemianopsia, papillary edema, and retrobulbar neuritis [12]. The vascular complications of OCP include central retinal artery or vein occlusion, intraocular hemorrhages, aneurysms, macular or disc edema, and acute ischemic optic neuropathy [13]. Also, they have been associated with high rates of cardiovascular events, venous thromboembolic disease, ischemic strokes, and breast cancer [14, 15].

There are also some studies concerning the effect of sex hormone fluctuations during the menstrual cycle on the eye. Some researchers have shown that these

Table 2 Comparison of macular and choroidal thickness in women using oral contraceptive pills and the control group

\begin{tabular}{|c|c|c|c|c|}
\hline \multirow[t]{2}{*}{ Parameter $(\mu \mathrm{m})$} & OCP group $(n=60)$ & Control group $(n=60)$ & $\mathrm{t}$ & \multirow{2}{*}{$\begin{array}{l}p^{-} \\
\text {value }\end{array}$} \\
\hline & Mean \pm SD & \multicolumn{2}{|l|}{ Mean \pm SD } & \\
\hline \multicolumn{5}{|l|}{ MACULA } \\
\hline Central subfield & $242.75 \pm 10.22$ & $268.13 \pm 11.86$ & 12.556 & $<0.001$ \\
\hline Superior inner macula & $293.88 \pm 10.48$ & $308.95 \pm 10.94$ & 7.704 & $<0.001$ \\
\hline Temporal inner macula & $295.48 \pm 7.58$ & $307.85 \pm 9.61$ & 7.828 & $<0.001$ \\
\hline Inferior inner macula & $295.63 \pm 8.52$ & $310.57 \pm 11.06$ & 8.288 & $<0.001$ \\
\hline Nasal inner macula & $298.95 \pm 10.31$ & $314.57 \pm 7.89$ & 9.316 & $<0.001$ \\
\hline Average inner macula & $296.0 \pm 8.05$ & $310.48 \pm 7.94$ & 9.922 & $<0.001$ \\
\hline Superior outer macula & $269.13 \pm 8.49$ & $282.97 \pm 11.31$ & 7.577 & $<0.001$ \\
\hline Temporal outer macula & $271.68 \pm 15.43$ & $284.45 \pm 11.59$ & 5.124 & $<0.001$ \\
\hline Inferior outer macula & $268.05 \pm 7.44$ & $286.38 \pm 10.40$ & 11.108 & $<0.001$ \\
\hline Nasal outer macula & $271.93 \pm 9.15$ & $301.22 \pm 13.33$ & 14.031 & $<0.001$ \\
\hline Average outer macula & $270.2 \pm 8.27$ & $288.75 \pm 8.71$ & 11.962 & $<0.001$ \\
\hline Cube volume $\mathrm{s}\left(\mathrm{mm}^{3}\right)$ & $8.71 \pm 0.50$ & $10.05 \pm 0.38$ & 16.539 & $<0.001$ \\
\hline Cube average thickness & $273.52 \pm 5.51$ & $284.73 \pm 6.18$ & 10.496 & $<0.001$ \\
\hline \multicolumn{5}{|l|}{ CHOROID } \\
\hline Temporal choroid & $219.87 \pm 6.26$ & $259.82 \pm 14.50$ & 19.595 & $<0.001$ \\
\hline sub foveal choroid & $233.98 \pm 9.34$ & $272.38 \pm 15.50$ & 16.433 & $<0.001$ \\
\hline Nasal choroid & $223.12 \pm 7.12$ & $260.23 \pm 16.82$ & 15.738 & $<0.001$ \\
\hline Average choroid & $225.66 \pm 7.12$ & $264.14 \pm 14.75$ & 18.2 & $<0.001$ \\
\hline
\end{tabular}


Table 3 Average peripapillary retinal nerve fiber layer thickness in women using oral contraceptive pills and the control group

\begin{tabular}{lllll}
\hline $\begin{array}{l}\text { Parameter } \\
(\mu \mathrm{m})\end{array}$ & $\begin{array}{l}\text { OCP group }(n=60) \\
\text { Mean } \pm \text { SD }\end{array}$ & $\begin{array}{l}\text { Control group }(n=60) \\
\text { Mean } \pm \text { SD }\end{array}$ & $\begin{array}{l}p- \\
\text { value }\end{array}$ \\
\hline superior & $103.38 \pm 9.97$ & $121.22 \pm 7.20$ & 11.232 & $<.937$ \\
Temporal & $59.83 \pm 7.22$ & $75.60 \pm 11.60$ & 10.137 & $<0.001$ \\
inferior & $112.28 \pm 14.80$ & $133.72 \pm 7.01$ & 13.624 & $<0.001$ \\
Nasal & $73.05 \pm 9.93$ & $99.67 \pm 11.42$ & 15.661 & $<0.001$ \\
Average & $87.14 \pm 8.77$ & $107.55 \pm 5.00$ & $<0.001$ \\
\hline
\end{tabular}

OCP Oral contraceptive pills. Values are expressed as mean \pm SD. $P$ values $\leq 0.05$ were considered significant

hormone fluctuations exhibited correlations with changes in ocular tissue. Tear production, stability, dryness, and inflammation were significantly related to hormonal fluctuations in the menstrual cycle. Impairment of these functions appeared to be related to the estrogen peak during the follicular phase, especially in patients with a dry eye [16]. During the menstrual cycle, the corneal thickness is thinner at the beginning of the cycle and thicker at the end [17]. Evaluation of the effects of the menstrual cycle on the choroidal thickness of healthy women of reproductive age showed a significant decrease in thickness in the mid-luteal phase of the menstrual cycle [18]. Also, the choroidal thickness measured by SD-OCT was reported to be significantly thinner in postmenopausal women than healthy reproductive-age women, which speculated to be secondary to menopausal estrogen deficiency [19].

In this study, we were evaluating the thickness of the macula, the RNFL, GCL, and CT in women who received OCP (0.03 mg ethinylestradiol and $0.15 \mathrm{mg}$ levonorgestrel) regularly for at least 1 year. We observed that the thickness of all the macular parameters, the cube macular volume, the RNFL, the GCL, and the CT decreased significantly in the OCP group compared to the control group. These thinning effect of the OCP are similar to age-related hormonal changes in which thinning of the macula is due to macular atrophy or RNFL atrophy [20]. In this study, these findings were not considered related to age since the average age of the women was $30.48 \pm 3.4$ years.
Apart from the study done by Madendag et al. [7] in 2017, concerning the effect of OCP on the thickness of the macula, the RNFL and the choroid using OCT, there are no other available data. Madendag et al. used OCP containing $0.03 \mathrm{mg}$ ethinylestradiol and $3 \mathrm{mg}$ drospirenone. They found that all OCT measurements of macular parameters were considerably decreased in the OCP group compared to the control group except the foveal center thickness which remained unchanged. They speculated that the absence of blood vessels in the fovea could be the cause of unaffected fovea. They also found that only the average of the RNFL, the nasal-inferior, and the temporal-inferior parts of the RNFL was considerably slimmer in the OCP group but the other parts of the RNFL remained unchanged. They also reported unchanged CT. They speculated that using a combined oral contraceptive could be the cause of unaffected CT since the estrogen is opposed by the progesterone.

In accordance with our study is that all macular variable values were considerably lower in the OCP group compared to the control. The same was applied to the cube macular volume which decreased in both studies. Controversial with our results is reporting thinning of only parts of the peripapillary RNFL and not all the parts. They also reported unaffected choroid. We reported significant thinning of all parts of RNFL, all parts, of GCL and the choroid.

We also compared our data of the control group regarding the MT, CT, and NFL thickness (Tables 2 and 3) with the normative data of other studies using SD-

Table 4 Average Ganglion cell layer thickness in women using oral contraceptive pills and the control group

\begin{tabular}{|c|c|c|c|c|}
\hline \multirow[t]{2}{*}{ Parameter ( $\mu \mathrm{m})$} & OCP group $(n=60)$ & Control group $(n=60)$ & $\mathrm{t}$ & \multirow{2}{*}{$\begin{array}{l}p^{-} \\
\text {value }\end{array}$} \\
\hline & Mean \pm SD & \multicolumn{2}{|l|}{ Mean \pm SD } & \\
\hline superior & $76.07 \pm 7.59$ & $86.78 \pm 4.88$ & 9.201 & $<0.001$ \\
\hline Superior Temporal & $76.07 \pm 6.97$ & $87.05 \pm 4.98$ & 9.928 & $<0.001$ \\
\hline Inferior Temporal & $76.38 \pm 6.69$ & $87.93 \pm 4.07$ & 11.428 & $<0.001$ \\
\hline Inferior & $75.80 \pm 6.67$ & $87.38 \pm 4.20$ & 11.386 & $<0.001$ \\
\hline Inferior Nasal & $76.35 \pm 7.30$ & $88.05 \pm 3.84$ & 10.987 & $<0.001$ \\
\hline Superior Nasal & $76.55 \pm 7.00$ & $87.55 \pm 3.60$ & 10.830 & $<0.001$ \\
\hline Average & $76.20 \pm 6.68$ & $87.46 \pm 3.40$ & 11.631 & $<0.001$ \\
\hline
\end{tabular}

OCP Oral contraceptive pills. Values are expressed as mean \pm SD. $P$ values $\leq 0.05$ were considered significant 
OCT. Liu et al. [21], using Cirrus HD-OCT reported CST of $262.4 \pm 22.8 \mu \mathrm{m}$, macular thickness (MT) of $281.3 \pm 14.5 \mu \mathrm{m}$, and macular volume (MV) of $10.1 \pm 0.6$ $\mathrm{mm}^{3}$, respectively. Manjunath et al. [22], reported mean subfoveal (CT) of $272 \pm 81 \mu \mathrm{m}$, showing a thin choroid nasally, thickest choroid sub-foveally, and thinner choroid temporally. Using Spectralis SD-OCT, Bindu et al. [23], provided the normative data of MT and RNFL thickness in Indians. They reported normal central foveal thickness of $260.1 \pm 18.19$ um. The nasal inner quadrant showed maximum retinal thickness $(338.88 \pm$ $18.17 \mathrm{um})$. The mean RNFL thickness was $101.43 \pm 8.63$ um with maximum thickness in the inferior quadrant. El-Hifnawy et al. [24, 25] collected normative MT and RNFL thickness data in the Egyptian population, the mean CST was $262.70 \pm 19.64 \mu \mathrm{m}$ and the mean NFLT was $101.74 \pm 10.05 \mu \mathrm{m}$. The mean MT values were significantly greater in men than in women and were found to be less than those seen in the studies published previously on Caucasians using Spectralis SD-OCT.

Although the values in our study are in the normative range of other studies, SD-OCT measurements cannot be compared between different machines because each technology's normative database is derived from a different population of different racial or ethnic groups. Sex and age also have an influential effect.

\section{Conclusions}

We conclude that women who are using OCP for more than 1 year could develop some eye problems which could involve the central vision. We also think that using OCP with different preparations could give different results. Further long term studies are required using different preparations of combined oral contraceptive pills (COC) or progestin-only contraceptive pills (POC) to find out what are the consequences of these changes when these thickness alterations can be clinically significant or symptomatic and if these changes are reversible or not. OCT should be routinely done for follow up these cases. According to these findings, physicians should take into consideration patients ocular history, before selecting the method of contraception and before prescribing OCP for reasons other than contraception.

\footnotetext{
Abbreviations

BMI: Body Mass Index; COC: Combined Oral Contraceptive Pills; CSF: Central Subfield; CST: Central Subfield Thickness; CT: Choroidal Thickness; GCL: Ganglion Cell Layer; MT: Macular Thickness; MV: Macular Volume; OCP: Oral Contraceptive Pills; POC: Progestin-Only Contraceptive Pills; RNFL: Retinal Nerve Fiber Layer; SD-OCT: Spectral Domain Ocular Coherence Tomography; SD-OCT: Spectral- Domain Ocular Coherence Tomography
}

\section{Acknowledgments}

The authors acknowledge the support of Dr. Mustafa HM, Professor of Community and Public Health, Faculty of Medicine, Ain Shams University, for performing the statistics of this study.

\section{Authors' contributions}

Both authors have participated sufficiently in the work and take responsibility for the content. Both participated in the concept, design, data collection, analysis, writing, and revision of the manuscript. YM performed all the Ocular Coherence Tomography for all the candidates. TB performed all the required ocular examination for all the candidates. Both authors have read and approved the manuscript in its current state.

\section{Funding}

There is no funding, or any payments involve this work by any person or any organization. The study was done as a part of the work in the ESC (Eye Subspecialty (enter). No one other than the authors has an interest in the outcome of the work. The authors did plan, design, conduct, prepare and edit the manuscript and they are responsible for the payment of APF.

\section{Availability of data and materials}

The data used to support the findings of this study are included in the article.

\section{Ethics approval and consent to participate}

The procedures performed in this study were in accordance with the ethical standards of the institutional and/or national research committee and with the 1964 Helsinki declaration and its later amendments or comparable ethical standards and approved by the Ethics Committee Of The Eye Subspecialty Center (ESC),18 El Khalifa El Maamoun Street, Heliopolis, 11402 Cairo, Egypt. The ESC Ethics Committee approved the use of verbal-only consent to participate in the study because (1) All the data in the study were collected through performing Spectral-Domain Optical Coherence Tomography (SD-OCT), which is a noninvasive imaging technique used for medical imaging, employed in clinical practice and does not require written consent, it uses light waves to take cross-section pictures of the retina). (2) The procedure was performed with no sedation or anesthesia, and no topical eye drops were instilled for corneal anesthesia or dilatation of the pupil before the test. (3) The possibility of discomfort expected in the study is not greater than those ordinarily happened during the performance of the routine ocular examination. For obtaining the informed verbal consent, the investigator reads and explains a verbal version of consent from an information sheet which includes most of the elements of a consent form (purpose, the procedure, and its duration, any risk of discomfort, benefits, the confidentiality of records, etc). All subjects were allowed to ask questions before giving their verbal consent.

\section{Consent for publication}

Not applicable.

\section{Competing interests}

The authors declare that they have no competing interests.

\section{Author details}

'Department of Ophthalmology, Faculty of Medicine, Ain Shams University, Abbassyia, Cairo 11566, Egypt. ${ }^{2}$ The Eye Subspecialty Center, (ESC), 18 El Khalifa El Maamoun Street, Heliopolis, Cairo 11402, Egypt. ${ }^{3}$ Cairo, Egypt.

Received: 7 March 2019 Accepted: 2 December 2019

Published online: 10 December 2019

\section{References}

1. Moschos MM, Nitoda E. The impact of combined oral contraceptives on ocular tissues: a review of ocular effects. Int J Ophthalmol. 2017;10:1604-10.

2. Gupta PD, Johar K Sr, Nagpal K, Vasavada AR. Sex hormone receptors in the human eye. Surv Ophthalmol. 2005;50:274-84.

3. Smith W, Mitchell P, Wang JJ. Gender, estrogen, hormone replacement, and age-related macular degeneration. Results from the Blue Mountains Eye Study. Aust NZJ Ophthalmic. 1997;25(Supp 1):S13-5.

4. Feskanich D, Cho E, Schaumberg DA, Colditz GA, Hankinson SE. Menopausal and reproductive factors and risk of age-related macular degeneration. Arch Ophthalmol. 2008;126:519-24.

5. Xu HP, Chen M, Forrester JV. Para-inflammation in the aging retina. Prog Retina Eye Res. 2009;28:348-68.

6. Deschenes MC, Descovich D, Moreau M, Granger L, Kuchel GA, Mikkola TS, Fick GH, Chemtob S, Vaucher E, Lesk MR. Postmenopausal hormone therapy 
increases retinal blood flow and protects the retinal nerve fiber layer. Invest Ophthalmol Vis Sci. 2010;51:2587-600.

7. Madendag Y, Acmaz G, Atas M, Sahin E, Tayyar AT, Madendag IC, Ozdemir F, Senol V. The effect of Oral contraceptive pills on the macula, the retinal nerve Fiber layer and the Choroidal thickness. Med Sci Monit. 2017;23:5657-61.

8. Wiegratz I, Thaler CJ. Hormonal contraception-what kind, when, and for whom? DtschArztebl Int. 2011;108:28-9.

9. Tomlinson A, Pearce El, Simmons PA, Blades K. Effect of oral contraceptives on tear physiology. Ophthalmic Physiol Opt. 2001;21:9-16.

10. Panisset A. Ocular complications of contraception. Union Med Can. 1975; 104:1549-50.

11. Kurtul BE, Inal B, Ozer PA, Kabatas EU. Impact of oral contraceptive pills on central corneal thickness in young women. Indian J Pharmacol. 2016:48(6):665-8.

12. Corcelle L. The eye and oral contraceptives. Annee Ther Clin Ophtalmol. 1971;22:157-63.

13. Pike MC. Hormonal contraception and breast cancer. Am J Obstet Gynecol. 2018:219:169.e1-4

14. Carlton C, Banks M, Sundararajan S. Oral Contraceptives and Ischemic Stroke Risk. Stroke. 2018;49:157-9.

15. Beaber EF, Buist DS, Barlow WE, Malone KE, Reed SD, Li Cl. Recent ora contraceptive use by formulation and breast cancer risk among women 20 to 49 years of age. Cancer Res. 2014;74:4078-89.

16. Versura P, Fresina M, Campos EC. Ocular surface changes over the menstrual cycle in women with and without dry eye. Gynecol Endocrinol. 2007;23:385-90.

17. Giuffre G, Di Rosa L, Fiorino F, Bubella DM, Lodato G. Variations in central corneal thickness during the menstrual cycle in women. Cornea. 2007:26:144-6.

18. Ulas F, Dogan U, Duran B, Keles A, Agca S, Celebi S. Choroidal thickness changes during the menstrual cycle. Curr Eye Res. 2013;38:1172-81.

19. Ataş M, Açmaz G, Aksoy H, Demircan S, Göktaş A, Arifoğlu HB, Zararsız G. Evaluation of the macula, retinal nerve fiber layer and choroid thickness in postmenopausal women and reproductive-age women using spectraldomain optical coherence tomography. Prz Menopauzalny. 2014;13:36-41.

20. Bonnel S, Mohand-Said S, Sahel JA. The aging of the retina. Exp Gerontol. 2003:38:825-31.

21. Liu T, Hu AY, Kaines A, Yu F, Schwartz SD, Hubschman JP. A pilot study of normative data for macular thickness and volume measurements using cirrus high-definition optical coherence tomography. Retina. 2011;31(9): 1944-50.

22. Manjunath V, Taha M, Fujimoto JG, Dukert S. Choroidal thickness in Normal eyes measured using cirrus-HD optical coherence tomography. Am J Ophthalmol. 2010;150(3):325-9.

23. Appukuttan B, Giridhar A, Gopalakrishnan M, Sivaprasad S. Normative spectraldomain optical coherence tomography data on macular and retinal nerve fiber layer thickness in Indians. Indian J Ophthalmol. 2014:62(3):316-21.

24. El-Hifnawy MA, Abo-Samra AA, Abou Shousha MA, Kassem EM. Retinal nerve fiber layer thickness in normal Egyptian population. Delta Ophthalmol. 2017;18:108-15.

25. El-Hifnawy MA, Gomaa AR, Abd El-Hady AM, Elkayal HE. Spectralis optical coherence tomography normal macular thickness in Egyptians. Delta J Ophthalmol. 2016;17:143-50.

\section{Publisher's Note}

Springer Nature remains neutral with regard to jurisdictional claims in published maps and institutional affiliations.

Ready to submit your research? Choose BMC and benefit from:

- fast, convenient online submission

- thorough peer review by experienced researchers in your field

- rapid publication on acceptance

- support for research data, including large and complex data types

- gold Open Access which fosters wider collaboration and increased citations

- maximum visibility for your research: over $100 \mathrm{M}$ website views per year

At $\mathrm{BMC}$, research is always in progress.

Learn more biomedcentral.com/submissions 